\title{
As Operações de Securitização de Dívida Ativa e suas Antinomias
}

\author{
Cláudio de Araújo Ferreira
}

\section{RESUMO}

O objetivo do presente artigo é tratar do tema da securitização de dívida ativa e as antinomias existentes e seu potencial papel na reconstrução do Estado brasileiro depois do fracasso do Lulo-petismo.

Vislumbrar a definição de dívida ativa e os principais entraves existentes para sua viabilização é o percurso a ser adotado. Ao longo desta obra também são abordados temas como moral hazard referente a não cobrança dos tributos e incentivos gerados em virtude desta ineficiência; volume de dívida ativa dos Estados e discussões sobre modelos de Estado; e mesmo os modelos de Estado existentes. 


\section{Lista de Abreviaturas}

CVM: Significa a Comissão de Valores Mobiliários

BNDES: Significa o Banco Nacional de Desenvolvimento

PIB: Significa o Produto Interno Bruto

SEC: Significa a Securities Exchange Commission

ITCMD: Significa o Imposto de Transmissão Causa Mortis e Doação

IPVA: Significa o Imposto Sobre Propriedade de Veículos Automotores

IPTU: Significa o Imposto Predial Territorial Urbano

ISS: Significa o Imposto Sobre Serviços

ICMS: Significa o Imposto Sobre Circulação de Mercadorias e Serviços

Dívida Ativa: Significa as possíveis definições estabelecidas no Capítulo 4 LRF: Significa a Lei Complementar $n^{0} 101$, de 4 de maio de 2000, também conhecida como Lei de Responsabilidade Fiscal

TCU: Significa o Tribunal de Contas da União

RPPS: Significa os Regimes Próprios de Previdência Social

REFIS: Significa Programa de Recuperação Fiscal ou Programas de Parcelamentos de Débitos

\section{Sumário}

\section{Introdução}

1. 0 papel do Estado e o Moral Hazard da não cobrança dos Tributos

2. A deterioração das contas públicas durante o período do Lulo-Petismo

3. Dívida Ativa

4. Securitização de Dívida Ativa e Antinomia das normas

\section{Conclusão}




\section{Introdução}

Desde a antiguidade a atividade Estatal é financiada por meio dos tributos. Em cima deste preceito é que a discussão sobre o papel do Estado se aprofunda. Qual seria o papel efetivo do Estado? Este deveria apenas prover os serviços básicos a população e regular as atividades econômicas, o que refletiria em uma baixa carga tributária ou este deveria ser um Estado "paternalista" e um agente efetivo na economia como um motor do crescimento, o que por consequência acarretaria em uma maior carga tributária? A depender da resposta a tal questionamento o Estado pode ser organizar nas formas de "Estado Liberal" ou "Estado Social". Independentemente de se falar de Estado Liberal ou Estado Social, ambos são financiados pelos tributos.

O Brasil viveu uma preponderância do modelo do Estado Social no período conhecido como "lulo-petismo" (2002-2016). Houve a criação de diversos programas sociais como "bolsa-família", "minha-casa-minha vida", "FIES" e "PROUNI". Neste período o Banco Nacional de Desenvolvimento ("BNDES") investiu diretamente em companhias brasileiras com 0 intuito de criar multinacionais brasileiras conhecidas como "campeões nacionais", além de ser o principal fomentador dos projetos de infraestruturas com taxas subsidiadas pelo Tesouro; o governo forçou uma redução artificial das taxas de juros e os bancos públicos expandiram o crédito; as companhias estatais foram investidoras ferrenhas dos projetos de infraestrutura, gerando "em tese" uma maior competição e melhores taxas para os usuários, sem falar nos fundos de pensão de companhias estatais atuando como agentes relevantes na realização de investimentos na economia real. Assim, com a adoção de uma política econômica expansionista e apoiado no crescimento mundial (impulsionado pelo crescimento da economia chinesa) e com a utilização do aparato estatal; 0 governo passou a ser o principal indutor do crescimento e o Brasil chegou a viver alguns anos dourados. Parecia que o momento do Brasil finalmente havia chegado. A taxa de crescimento do Produto Interno Bruto chegou a atingir o 
patamar de 7\% em 2010; o Brasil foi reconhecido como "grau de investimento" pelas agências de rating internacionais; a Bovespa atingiu seu auge atraindo um grande volume de investimento estrangeiro e a população brasileira atingiu uma melhora de vida e mobilidade social.

Porém, como já dizia Milton Friedman, não existe "almoço grátis"1. A partir de 2013 a economia brasileira começa a mostrar sinais do esgotamento do modelo de crescimento apoiado na expansão do consumo. As reformas estruturais como a tributária, trabalhista e previdenciária não foram realizadas. 0 gasto público saiu de controle. O governo interveio na economia em diversos setores contrariando regras básicas na economia de livre mercado e chegamos em 2015 com a maior crise econômica das últimas décadas (estagnação da atividade econômica com altos índices de desemprego), sem mencionar a existência de uma crise política, em que as principais lideranças políticas do país se mostraram envolvidas em grandes escândalos de corrupção.

Neste cenário de estagnação da economia e redução da arrecadação estatal é que temas como o saneamento das contas públicas ganham grande relevância. Em momentos como este é que também a discussão sobre o aumento de tributos costuma vir à tona.

Milton Friedman diz que se o deserto do Saara for gerido por uma empresa estatal, em 5 anos a areia tende a acabar. Assim, antes de se falar em novos tributos o Estado deveria olhar para o estoque de dívida ativa tanto no âmbito federal como estadual ou municipal. Apenas a título de exemplo, o Estado de São Paulo possui cerca de R\$270 bilhões de Dívida Ativa, montante mais do que suficiente para equacionar a sua queda de receita. Neste sentido, o Estado deveria cobrar os tributos já lançados para somente depois falar criar novos tributos.

Operações como securitização de Dívida Ativa poderiam vir a se tornar uma grande alavanca do equacionamento das finanças públicas brasileiras. Porém, considerando o arcabouço de normas existente, há potenciais antinomias e conflitos de interesse que precisariam ser equacionados para viabilizar tais

\footnotetext{
${ }^{1}$ Safire, William On Language; Words Left Out in the Cold" New York Times, 2-14-1993 (em inglês)
} 
operações. Este artigo visa tratar sobre este tema, sendo que o aprofundamento deste será objeto de dissertação de doutorado do presente autor.

\section{O papel do Estado e o Moral Hazard gerado pela não cobrança dos Tributos}

Os Estados podem se organizar na forma de Estado Liberal, na qual Estado possui como finalidade regular a atividade econômica e preservar as liberdades individuais ou na forma de Estado Social, na qual verificamos um Estado paternalista regulando temas vida cotidiana da população e com forte intervenção na economia.

Independentemente da forma preponderante de organização do Estado este se financia por meio da cobrança de tributos. Conforme poderá observado no Capítulo 3 a seguir, os estados e municípios possuem um estoque de dívida ativa superior a bilhões de reais, o que seria mais do que suficiente para sanar o déficit público brasileiro, estimado para 2016 em R $\$ 170$ bilhões, conforme proposta aprovada pelo Congresso Nacional.

Neste capítulo a idéia é também discutir o conceito de Moral Hazard envolvendo a existência de um estoque de tributos não cobrados pelo Estado. Gustavo Franco definiu moral hazard a partir de sua tradução literal do inglês (que seria "risco moral") como "tentação do imoral", ou seja, há comportamentos viciosos, porém racionais, como por exemplo o caso do sujeito que contrata um seguro e passa a ser mais desleixado com o respectivo bem ${ }^{2}$. Para este autor o ser humano é movido a incentivos. Um dos princípios principais de direito para eficácia de uma norma é o da possibilidade de coercibilidade, ou seja, se não há cobrança, o sujeito não possui o incentivo correto para realizar o pagamento. Assim, se o Estado não cobra o respectivo tributo não há incentivos que os contribuintes realizem seu pagamento. Ainda, sem contar com o fato de que de

\footnotetext{
${ }^{2}$ As Leis Secretas da Economia: Revisitando Roberto Campos e as Leis do Kafka. Franco, Gustavo H. B. Ed. Zahar, 200_pg. 49
}

http://revistasapereaude.org/index.php/edicoes/ano-5-volume-1-agosto-2016 
tempos em tempos este cria programa de incentivos para a cobrança de tributos atrasados conhecidos como "REFIS"; qual o incentivo para os contribuintes pagarem seus tributos na data correta? Por outro lado, qualquer credor deveria buscar recuperar seus créditos em atraso e é comum no mercado a existência de concessão de descontos, parcelamento, etc., o que gera um potencial conflito. Ou seja, os incentivos (descontos/perdão de multa/parcelamentos) não podem ser mais atraentes do que pagar o tributo na data correta, porém devem incentivar os contribuintes a quitar com suas dívidas com o Estado.

\section{A deterioração das contas públicas durante o Lulo-Petismo}

Em 2002 após 8 anos do governo Fernando Henrique, Lula toma é eleito presidente do Brasil. Lula assume um governo com uma economia estabilizada com o sucesso do Plano Real e com diversas conquistas obtidas como a Lei de Responsabilidade Fiscal, independência das agências reguladoras, reforma da previdência e com o desafio de manter a economia nos trilhos e prosseguir com as reformas estruturais como reforma tributária, reforma política, reforma trabalhista, entre outras. Ao longo dos 14 anos (de 2002 a 2016) nenhuma destas reformas foi realizada e no segundo mandato de Lula começa a se verificar um abandono gradual da política econômica que de Fernando Henrique, havendo uma ruptura no governo Dilma Roussef com o estabelecimento da nova matriz econômica calcada na expansão do crédito e redução artificial das taxas de juros.

Neste período houve a criação de diversos projetos sociais como "bolsa-família", "minha-casa-minha vida", "FIES" e "PROUNI". O Banco Nacional de Desenvolvimento ("BNDES") investiu diretamente em companhias brasileiras com o intuito de criar multinacionais brasileiras conhecidas como "campeões nacionais", além de ser o principal fomentador dos projetos de infraestruturas com taxas subsidiadas pelo Tesouro; os bancos públicos expandiram o crédito desenfreadamente; e o governo interveio de maneira desastrosa em diversos setores. A título de exemplo, a Medida Provisória 579/2012 nas empresas do setor Elétrico fez com que a Eletrobras perdesse mais de $50 \%$ de seu valor de 
mercado. O desemprego brasileiro que havia atingido patamares mais baixos da história (patamares de 6\%) saltou para 11\% em 2016.

Ou seja, todos estes fatos demonstram que chegou a conta pela gastança desenfreada ocorrida e que se não forem realizadas as reformas necessárias e saneamento das despesas o Estado brasileiro pode chegar a uma situação próxima da "Falência". Estes dados corroboram a tese de que o modelo de "Capitalismo de Estado do Lulo-Petismo" fracassou.

\section{Dívida Ativa}

Dívida Ativa pode ser definida como o conjunto de créditos originários de tributos não pagos que compõem o ativo dos entes públicos. No âmbito dos Estados temos como exemplo de dívida ativa os seguintes tributos: ICMS, IPVA e ITCMD, enquanto que no âmbito municipal podemos citar tributos como o IPTU e o ISS.

Os maiores estados em volume de Dívida Ativa são (em volumes estimados): 10 lugar São Paulo com R\$290 bilhões; $2^{\circ}$ lugar Rio Janeiro com R 120 bilhões; $3^{\circ}$ lugar Minas Gerais com R\$ 45 bilhões; $4^{\circ}$ lugar com $\mathrm{R} \$ 33$ bilhões e $5^{\circ}$ lugar Santa Catarina com $\mathrm{R} \$ 20$ bilhões. No que tange aos municípios temos: $1^{\circ}$ lugar São Paulo com R $\$ 73$ bilhões; $2^{\circ}$ lugar Rio de Janeiro com R\$ 37 bilhões; e em $3^{\circ}$ Salvador com R4 19 bilhões. ${ }^{3}$

\section{Securitização de Dívida Ativa e Antinomia das Normas}

Ao longo do Capítulo 2 foi possível ter uma suscinta uma idéia do nível da deterioração das finanças públicas brasileiras e no Capítulo 3 uma idéia do volume de estoque de Dívida Ativa. Este estoque seria mais do que suficiente

\footnotetext{
${ }^{3}$ www.tesouro.gov.br
} 
para resolver ou ser parte da solução da situação de nossas finanças públicas, desde que possa ser transformado em "liquidez" efetivamente.

Uma das maneiras de transformar este estoque seria por meio da realização de sua cobrança. Pela nossa constituição federal, compete às procuradorias a cobrança da Dívida Ativa da União e dos Estados. Claramente, considerando as estruturas existentes das procuradorias, estas não são suficientes para a realização de cobrança da Dívida Ativa pulverizada/varejo.

Em se tratando de municípios, não há a mesma reserva de prerrogativa das procuradorias e da mesma forma que ocorre com os Estados, as procuradorias municipais também não possuem estrutura adequada para cobrança da Dívida Ativa, ou seja, há uma maior flexibilidade para terceirização destes serviços. No setor privado as cobranças pulverizadas são realizadas por empresas especializadas em gestão de cobranças que subcontratam empresas de cobrança com milhares de funcionários estruturados na forma de call center, com aparato tecnológico, banco de dados alimentado diariamente, profissionais especializados em estatística e modelos macro.

A título de exemplo, o nível de recuperação de dívida ativa do Estado de Goiás é na ordem de $0,5 \%$ ao ano enquanto que, conforme estimativa de um agente privado que atua neste segmento, este número poderia ser 4-5 vezes maior.

Além da cobrança de maneira mais eficiente, uma das maneiras de levantar recursos utilizando os montantes do estoque de Dívida Ativa seria por meio da realização de operações de securitização destes recebíveis. 0 termo securitização vem da palavra em inglês securities que traduzido para 0 português significa "valores mobiliários". Valores Mobiliários são títulos de propriedade emitido por um ente que confere a seu titular determinados direitos financeiros e de governança. Assim, por securitização de recebíveis podemos entender como a estruturação de uma operação por meio da qual um determinado fluxo de recebíveis passa a ser o lastro de um valor mobiliário, o qual é distribuído no mercado (de maneira pública ou privada) para captação de recursos. 
As operações de securitização mais comuns no mercado brasileiro são aquelas realizadas no mercado imobiliário, representadas pelos Certificados de Recebíveis Imobiliários. Compete às companhias securitizadoras e emissão destes ativos. De maneira a preservar os investidores, estas securitizadoras possuem o regime fiduciário e patrimônio segregado, o qual estabelece que as respectivas emissões são patrimônio segregado no âmbito da securitizadora, evitando que o problema em uma emissão contamine as demais.

Desta forma, considerando o alto volume de estoque de Dívida Ativa, uma operação que no curto prazo poderia gerar grandes volumes de receita aos entes públicos seria

Porém, existe um entrave jurídico a realização de tais operações. Conforme interpretação do TCU, as operações de securitização de Dívida Ativa estariam vedadas pela Lei de Responsabilidade. Esta vedação é oriunda do entendimento do TCU ao artigo 37 da LRF que obriga os entes públicos a obter autorização do Senado Federal e da Receita Federam para contrair empréstimos. Segundo este entendimento, refletido pela ata 01/2015, operações de securitização de Dívida Ativa seriam operações de crédito. Além deste óbice, há uma discussão em torno da limitação a utilização de qualquer benchmark diferente daquele previsto na LRF. Por exemplo, tal ponto inviabilizaria securitizações atreladas a inflação. Sobre a interpretação sobre a natureza das operações de securitização de Dívida Ativa, este autor claramente discorda, uma vez que securitização, desde que não haja a obrigação com alguma rentabilidade mínima ou pagamento de juros obrigatório, constitui na alienação de um ativo do respectivo ente e não na contratação de empréstimos, uma vez que o ente não estaria se desfazendo de créditos futuros e não constituídos ainda, mas sim estaria desfazendo de uma ativo de balanço.

Os pareceres do TCU não são vinculantes, porém, da maneira como nossa legislação foi estabelecida, os agentes públicos não costumam confrontar tais pareceres, o que, em termos práticos inviabiliza a realização de tais operações com o arcabouço jurídico existente.

http://revistasapereaude.org/index.php/edicoes/ano-5-volume-1-agosto-2016 
A LRF foi estabelecida por meio de lei complementar o que quórum qualificado para alterá-la. Assim, para viabilização das operações de securitização de dívida ativa é necessária uma lei complementar.

Desta forma, podemos dizer que há uma antinomia nas operações de securitização de Dívida Ativa, já que a LRF não veda tais operações, sendo que um parecer do TCU é que inviabiliza a realização de tais operações. Neste sentido, há uma discussão do respectivo enquadramento do conceito de securitização de Dívida Ativa para efeitos e LRF e há uma discussão sobre a vinculação aos pareceres do TCU do lado jurídico e também do lado prático.

Para Hans Kelsen, há antinomia quando "uma norma determina uma certa conduta como devida e outra norma determina também como devida outra conduta, inconciliável com aquela" 4 .

\section{Conclusão}

Como consequência das gastanças do período conhecido como capitalismo de estado ou Lulo-Petismo, as finanças públicas brasileiras encontram-se deterioradas necessitando de soluções rápidas para seu saneamento. Em situações como essa todos os entes públicos avaliam a possibilidade de aumentar sua receita por meio do aumento dos tributos. Entretanto, conforme foi verificado ao longo do presente artigo, tais entes não deveriam falar em aumentar tributos e sim cobrar o estoque de Dívida Ativa atualmente existente de formas mais eficientes que as atuais.

Entretanto, verifica-se uma antinomia jurídica que inviabiliza em muitos casos a cobrança efetiva da Dívida ativa pelos entes ou mesmo a realização de operações de securitização de recebíveis que possibilitaria o ingresso de recursos no curto prazo nos cofres públicos sem o aumento de imposto.

Dois pontos apresentam-se como potenciais obstáculos, quais sejam: (i) a existência de normativo estabelecendo a competência das procuradorias para realização de cobrança de dívida ativa; e (ii) o possível enquadramento de operações de securitização de recebíveis de Dívida Ativa como violação de LRF.

\footnotetext{
${ }^{4}$ KELSEN, Hans. Teoria Pura do Direito. $7^{\mathrm{a}}$ ed. São Paulo: Saraiva, 2009.
}

http://revistasapereaude.org/index.php/edicoes/ano-5-volume-1-agosto-2016 
Importante ressaltar que se apenas o item (ii) fosse superado, a questão das prerrogativas das procuradorias inviabilizaria sua efetiva materialização, uma vez que possíveis interessados na realização de operações de securitização de Dívida Ativa possivelmente venham a exigir que terceiros privados realizem a cobrança da Dívida Ativa e não as procuradorias estaduais.

Tais pontos inviabilizam a solução apresentada para saneamento das finanças públicas e somente poderiam ser superados por meio edição de legislação específica pelo congresso nacional. Em se tratando da questão das procuradorias, seria necessário e aprovação de uma Emenda Complementar ou retirando tal prerrogativa como da procuradoria ou permitindo que esta subcontrate os serviços de apoio a cobrança. No que tange a securitização de recebíveis de Dívida Ativa, uma vez que a LRF é uma lei complementar, faz-se necessária a edição de outra Lei Complementar. 